\title{
RETAIL SALES PULL FACTORS IN U.S. COUNTIES
}

\author{
H. Frederick Gale, Jr.*
}

\begin{abstract}
Retail sales pull factors provide information about the ability of communities to attract and retain retail trade. This study reviews the regional retail trade concepts underlying pull factor formulas, estimates the relationship between retail sales and personal income, and uses that information to compute pull factors for all U.S. counties for 1982, 1987, and 1992. The results confirm the trend toward increased sales leakage for more rural counties. Higher population density, lower farm reliance, larger county size, and interstate highway access are associated with higher pull factors.
\end{abstract}

\section{DECLINE OF RETAIL TRADE}

A number of studies have raised concern about the decline of the retail sector in rural communities. Ayres et al. (1992) cite a study by Stone and McConnen (1980) that found a steady increase in sales leakage from small towns in four Midwestern states from 5 percent in the 1950s to 15 percent in the 1970s. Ayres reports that leakage was over 20 percent in lowa during the 1980s. Other studies that found retail trade shifting away from rural areas in the 1980s include Senf (1988) for Minnesota, Yanagida, et al. (1991) for Nebraska, Darling and Tan (1990) for Kansas, and Gruidl and Andrianacos (1994) for Illinois. The popular press has also given considerable attention to decline in rural retail trade. Retail trade has been a focus of much attention because the ability of a community to attract and retain retail trade is an important indicator of its economic health (Deller, et al., 1991).

The studies cited above focused on single states or regions in the Midwest or Great Plains, and generally covered the 1980 s, when a farm financial crisis was having adverse impacts on the retail sector in rural areas of those regions (Stone 1987). The current study provides more general and more recent information about the performance of the retail sector in counties of various types across the United States by estimating retail sales pull factors for all U.S. counties, using data from the 1982, 1987 and 1992 Censuses of Retail Trade. The results are the first comprehensive information on the magnitude and degree of variation in retail sales leakage or drawing power across all United States regions. By comparing pull factors for over the 1982-1992 period, we are able to evaluate whether sales leakages are increasing in rural counties. Exploratory analysis is conducted to determine how sales leakage varies by region and county characteristics. This in-

"Economist, Rural Economy Division, USDA-ERS. 
formation will be useful for researchers, government officials and economic development officials examining regional differences in retail sales patterns and evaluating the local economic impact of retail sales leakages. The results also provide a context for evaluating other analysts' estimates of pull factors for individual counties or regions.

The article begins by reviewing regional retail trade concepts that underlie pull factor formulas. The following sections explore the relationship between aggregate per capita sales and per capita income to develop a method for computing pull factors and estimate the sales-income relationship using Census of Retail Trade data. The results are used to compute pull factors for all U.S. counties. Finally, descriptive statistics and regression analyses are presented to explore the variation in pull factors across regions and types of counties.

\section{REGIONAL RETAIL TRADE CONCEPTS}

Spatial patterns of retail trade are usually discussed in the context of central place theory (Harris and Shonkwiler, 1994). Analysts usually assume, at least implicitly, that consumers are located spatially across a barrier-free plain in a pattern that is exogenous to the decision of where to shop. Clearly, this type of analysis is most appropriate for areas of the Midwest, Great Plains, and Inter-mountain regions that best fit the central place paradigm. This type of analysis is less suited to coastal, mountainous, and urbanized areas. When retail businesses experience size economies over some levels of output, and consumers are mobile with relatively low transportation costs, retail trade tends to become concentrated in central places (Fox 1962). Alternatively, Mulligan (1984) and Thill (1992) show that spatial concentration of retail establishments can result when economies of scope and multipurpose shopping trips by consumers make it optimal for firms selling complementary products to locate next to one another.

When retail trade is concentrated in central places, the supply of retail goods at a particular point on the plain does not necessarily match the demand at that point. The demand for retail goods to be consumed at location $\mathrm{i}, \mathrm{z}_{\mathrm{i}}^{\mathrm{d}}$, varies with the number of consumers residing at location $i\left(N_{i}\right)$, their per capita income $\left(y_{i}\right)$, and other characteristics and factors $\left(\mathbf{X}_{\mathbf{i}}\right)$ such as relative prices of goods, interest rates, tastes and preferences,

$$
Z_{i}^{d}=f\left(N_{i}, y_{i}, X_{i}\right)
$$


The supply of goods sold at location i (retail sales) is,

$$
Z_{i}^{s}=M_{i} z_{i}^{S},
$$

where $\mathrm{M}_{\mathrm{i}}$ is the number of retail outlets at location $\mathrm{i}$, and $\mathrm{z}_{\mathrm{i}}{ }^{\mathrm{s}}$ is the sales per outlet. The location of retail outlets (and thus $\mathrm{M}_{\mathrm{i}}$ ) and the average sales of each outlet $\left(\mathrm{z}_{\mathrm{i}}^{\mathrm{s}}\right)$ is determined through spatial competition. Since consumers may travel outside across regional boundaries, in equilibrium local demand for retail goods at location i need not equal local sales. Rather, the equilibrium condition is that sales equal purchases aggregated over some larger region, containing $\mathrm{T}$ locations:

$$
\sum_{i=1}^{T} Z_{i}^{d}=\sum_{i=1}^{T} Z_{i}^{s}
$$

The interaction of utility-maximizing consumers subject to transport costs with profit-maximizing sellers determines the spatial distribution of retail goods supply $\left(\mathrm{M}_{\mathrm{i}}\right.$ and $\left.\mathrm{z}_{\mathrm{i}}^{\mathrm{S}}\right)$, given the spatial distribution of retail goods demand. A combination of low transportation costs for consumers, high transportation costs for distribution of goods to retail outlets, economies of size for retail sellers, and low population density may result in the geographic concentration of retail trade. Retail sales leakage, $L_{i}$, can be defined as the difference between retail sales and consumption of retail goods at location $\mathrm{i}$ :

$$
L_{i}=Z_{i}^{d}-Z_{i}^{s},
$$

Sales leakage is positive when purchases by residents exceed sales by businesses. Trade center locations that attract trade from other locations will have $\mathrm{L}_{\mathrm{i}}<0$, and $\Sigma_{\mathrm{i}} \mathrm{L}_{\mathrm{i}}=\mathbf{0}$.

\section{Estimating Pull Factors}

The pull factor is a simple empirical measure of a community's retention of retail sales commonly used by economic development practitioners (Shaffer 1989; Harris et al. 1990). The pull factor has been defined in several different ways, but it is always a ratio of the actual retail sales captured in an area to the potential retail sales of the resident population in the area. Using the above framework, the pull factor for location $\mathrm{i}$ can be defined as the ratio, 


$$
P F_{i}=\frac{Z_{i}^{s}}{Z_{i}^{d}}
$$

A pull factor exceeding 1.0 indicates that region $i$ attracts sales exceeding the purchases of region i's residents $\left(\mathrm{L}_{\mathrm{i}}<0\right)$, while a pull factor less than 1.0 indicates retail sales leakage $\left(L_{i}>0\right)$.

Estimation of a pull factor requires estimates of $Z_{i}^{d}$, the potential retail demand in a county, and $Z_{i}^{\mathrm{s}}$, actual sales. Data on actual sales are available from Census of Retail Trade publications or from state sales tax records. Retail demand for a county, however, is not observed, since county sales do not necessarily equal county retail demand. Therefore, an important initial step is the estimation of $Z_{i}^{d}$. Many studies assume that demand is a fixed amount per capita, and use per capita sales for a state or other large region (for which supply equals demand, as in equation (3)) to estimate the denominator of (5). Algebraically, this is represented by

$$
Z_{i}^{d}=\bar{z} N_{i}
$$

where $\bar{z}$ is estimated by per capita sales at the state level, and $\mathrm{N}_{\mathrm{i}}$ is population. Others have adjusted per capita sales for the county's relative per capita income (Deller et al. 1991; Harris et al. 1990; Shaffer 1989; and Yanagida et al. 1991).

$$
Z_{i}^{d}=\bar{z}\left(\frac{y_{i}}{\bar{y}}\right) N_{i}=\alpha_{1} y_{i} N_{i},
$$

Where $y_{i}$ is county per capita income, $\bar{y}$ is state per capita income, and $\alpha_{1}$ is estimated by $\bar{z} / \bar{y}$, the ratio of state retail sales to state income. Equation (6) assumes that per capita retail demand is fixed, insensitive to income level, while (7) assumes that per capita retail demand increases proportionately with per capita income.

This study adjusts per capita retail demand for differences in per capita income without imposing the restrictive assumptions of equations (6) and (7). In general, the relationship can be written as a linear relationship,

$$
z_{i}^{d}=\alpha_{0}+\alpha_{1} y_{i}+e_{i},
$$

where $z_{i}^{d}$ is per capita demand for retail purchases in county $i, y_{i}$ is per capita income, and $e_{i}$ represents random influences. ${ }^{1}$ If the parameters $\alpha_{0}$ and $\alpha_{1}$ can be estimated, predicted values from these regressions can then be used to estimate retail demand in counties. The sales-income relationships embodied in equations (6) and (7) are special cases of equation (8). When $\alpha_{1}=0, \alpha_{0}=\bar{z}$, corresponding to 
the constant per capita sales assumption of (6). When $\alpha_{0}=0$, then $\alpha_{1}=\bar{z} / \bar{y}$, corresponding to (7).

With estimates $\hat{\alpha}_{0}$ and $\hat{\alpha}_{i}$, the pull factor can be computed with,

$$
P F_{i}=\frac{Z_{i}^{5}}{\left(\hat{\alpha}_{0}+\hat{\alpha}_{1} y_{i}\right) N_{i}}
$$

As has been noted above, county retail sales often do not equal county demand. Therefore, since county demand is not observed, equation (8) cannot be estimated with county-level data. This problem can be overcome by estimating equation (8) with data aggregated over a larger area for which total retail sales approximately equal total retail demand.

This study uses Rand McNally basic trading areas as the unit of observation to estimate (8). Trading areas are groups of counties that define a retail market surrounding a major city or town that serves as a market or trade center. The boundaries were drawn by Rand McNally based on transportation networks, physiography, economic activities, field reports by sales analysts, and newspaper subscriptions (Rand McNally, 1990). These regions appear to be the best available to define a retail market, and this study assumes that retail trade is self-contained within the trading area. It is common for consumers to travel outside their county to make routine retail purchases, but it seems likely that consumers would make nearly all of their retail purchases within a trading area. Close inspection of the data indicates that some trading areas pull in retail sales from outside the area through travel or tourism, and others may have sales leakage, but for most trading areas the assumption that retail trade is self-contained seems reasonable. ${ }^{2}$

Assuming that aggregate sales for a trading area equal aggregate retail demand for that area and that per capita income does not enter into the retail goods supply function permits identification of equation (8). Using the trading area as the unit of observation, trading area per capita sales can be used as the dependent variable in estimating equation (8), with trading area per capita income as the independent variable.

\section{Estimating the Sales-Income Relationship}

The most comprehensive data on retail trade are published in the Census of Retail Trade at five-year intervals (U.S. Bureau of the Census 1994). The Geographic Area Series reports retail sales by county and for places with population of 2,500 or more. This study used county data from 1982,1987 , and $1992 .{ }^{3}$ The county data on retail sales were matched with county-level personal income 
and population data obtained from the Bureau of Economic Analysis (1995). Personal income by place of residence includes wages and salaries, proprietors' income, transfer payments, dividends, interest and rent. A preferred measure would be personal disposable income, but it is not available at the county level.

County data were aggregated to the 487 Rand McNally basic trading areas to examine the relationship between per capita sales and per capita income. A linear regression was fit to these data using ordinary least squares to estimate $\alpha_{0}$ and $\alpha_{1}$. The resulting equations are:

$\begin{array}{ll}\text { 1982: } & \mathrm{z}=\begin{array}{l}1431 \\ (142)\end{array} \\ \text { 1987: } & \mathrm{z}=\begin{array}{l}0.293 \mathrm{y}, \\ (0.014)\end{array} \\ & \begin{array}{l}1172 \\ (197)\end{array}\end{array}$

where $\mathrm{z}$ represents per capita retail sales, $\mathrm{y}$ is per capita personal income, and standard errors are shown in parentheses. The regression results confirm the positive relationship between sales and income. The equation for 1987 suggests that a $\$ 100$ increase in income is associated with a $\$ 33.60$ increase in sales. The 1982 and 1992 results suggest a smaller response of $\$ 29.40$ and $\$ 24.10$, respectively, in sales to a $\$ 100$ increase in income. Income explains only half of the variation in sales for 1982 and 1987, and less than one-third for 1992. Apparently, other factors besides income affect per capita sales. ${ }^{4}$ Statistical tests confirm that these regression equations are superior to the assumptions of constant per capita sales or sales as a constant share of income. Likelihood ratio tests reject the hypotheses that $\alpha_{1}=0$ (per capita sales are independent of income), and $\alpha_{0}=0$ (sales are a constant proportion of income). A model based on the constant proportion of income assumption for 1992 explains only 16 percent of the variation in sales, compared with the full regression model that explains 32 percent.

\section{Computing Pull Factors}

For pull factor computation, it is assumed that the $\hat{\alpha}_{i}$ estimates obtained from trading area data also describe the marginal propensity to spend income on retail purchases for counties. This seems reasonable, since using a per capita specification for equation (8) assumes that total retail sales are homogeneous with degree 1 
in population. Further, many counties fall within the range of sizes/populations of the trading areas used to estimate $\hat{\alpha}_{i}$.

A predicted value of per capita sales was computed for each county by using county per capita income and the coefficients from the retail sales regression model estimated from trading area data. A different $a_{01}$ parameter was computed for each trading area, $t$, to ensure that the sum of predicted retail spending equaled actual sales in each of the 487 trading areas. Using equation (8) to represent spending, this implies the identity,

$$
\sum_{i=1}^{T} Z_{i}=\sum_{i=1}^{T}\left(\hat{\alpha}_{0 t}+\hat{\alpha}_{1} y_{i}\right) N_{i}
$$

where the summation is over T counties in a trading area. Equation (10) was solved for the intercept parameter $\alpha_{0}$ using county values of population and income, and the estimated value of $\alpha_{1}$ :

$$
\hat{\alpha}_{0 t}=\frac{\sum_{i=1}^{T} Z_{i}-\hat{\alpha}_{1} \sum_{i=1}^{T} Y_{i}}{\sum_{i=1}^{T} N_{i}}
$$

here $Y_{i}$ is total personal income in county $i$, and $T$ is the number of counties in trading area $t$. The pull factor was then computed using equation 9 . Note that the pull factor computation reduces to the constant per capita sales assumption (eq. 6) if $\alpha_{1}=0$, and to the constant share of income assumption (eq. 7) if $\Sigma_{I} Z_{i}=\alpha_{1} \Sigma_{I} Y_{i}{ }^{5}$

\section{ANALYSIS OF PULL FACTORS}

\section{The Pull Factor Distribution}

Counties were divided into two groups: those containing a trade center town or city, and those without a trade center. A trade center is the highest-order central place in a trading area where retail businesses tend to be concentrated. Counties with a trade center are expected to have pull factors greater than 1.0, while other counties in the surrounding tributary region or trade-shed will tend to have lower pull factors. Trade centers for each basic trading area were identified using the 
map of trading areas published by Rand McNally (1990). The number of trade center counties, 548, exceeds the number of trading areas because a number of trading areas had more than one trade center.

The distribution and descriptive statistics of estimated pull factors by trade center status for 1992 are shown in Figure $1 .^{6}$ As expected, the distributions for trade center and non-trade center counties are very different. The distribution for non-trade center counties is fairly symmetric within the range from 0.50 to 1.09 , but the lower tail has slightly more weight (18 percent less than 0.50 ) than the upper tail (12 percent over 1.09), as might be expected. There is considerable variation in pull factors for non-trade-center counties. The standard deviation is .316 (40 percent of the mean), and the two modal categories, $0.70-0.79$ and 0.80 0.89 , combined contain only 28 percent of counties. The mean pull factor for non-

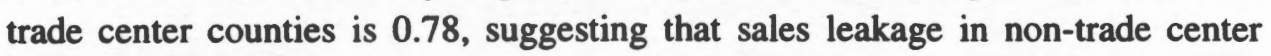
counties averages 22 percent.

As expected, the distribution for trade center counties is much different. It shows less symmetry than the non-trade center distribution, has a higher mean of 1.11 , and has less spread. The mean for trade center counties suggests that retail trade attracted from outside these counties increases their sales by 11 percent. About ten percent of counties classified $a$ priori as trade center counties have pull factors less than 1.0. About 40 percent of trade center counties lie in the 1.00-1.09 interval, and a little over 20 percent are in the 1.10-1.19 interval. The 1.40-1.49 and 1.50-and-higher categories each contain about 2 percent of counties. ${ }^{7}$

\section{Effects of Urbanization and Region}

Variation in pull factors with respect to urban-rural and trade center status is now examined. This analysis explores the concerns raised by Ayres et al. (1992), Senf (1988), Yanagida, et al. (1991), Darling and Tan (1990), and Gruidl and Andrianacos (1994) about increasing sales leakage in rural communities. The analysis compares mean pull factors for counties with different degrees of urbanization by trade center status to evaluate the degree of sales leakage in rural vs. urbanized counties. Changes in pull factors over the 1982-92 time period are also considered, with particular attention given to the most rural counties to determine the extent to which sales leakage is increasing. Previous studies suggest that more rural counties have pull factors that are not only lower than more urbanized counties, but also falling over time. Comparisons across regions examine whether the high and increasing sales leakage in rural counties found in previous studies of midwestern states apply to other regions. Finally, regression analysis explores the role of county characteristics in determining variation in pull factors for non-trade center counties. 
FIGURE 1

Distribution of County Retail Sales Pull Factors, 1992

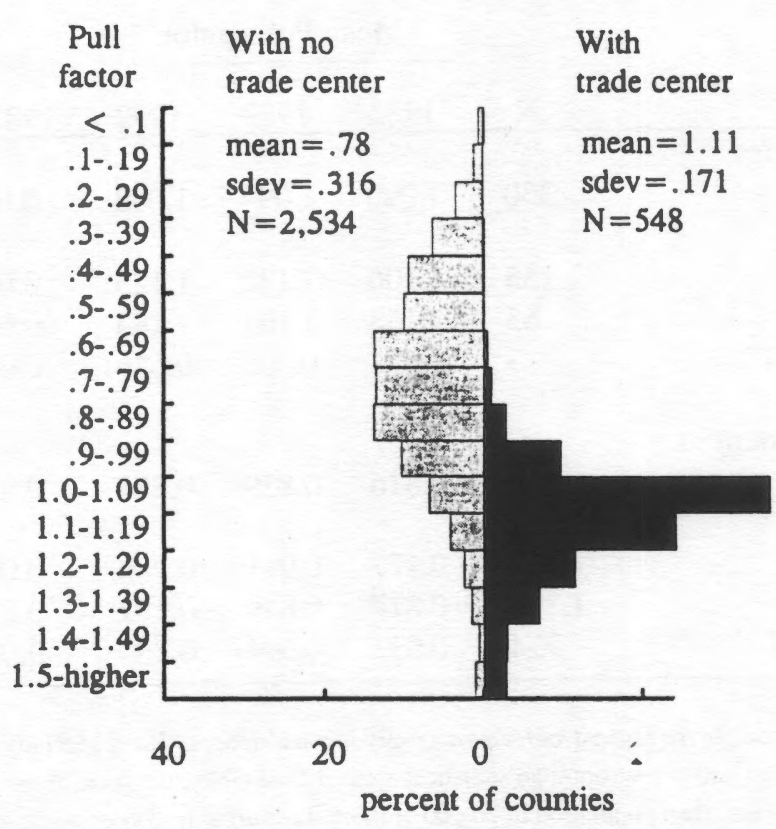

The measure of urbanization in this study is a simplified version of the ruralurban continuum code published by Butler. Counties fall into one of four categories, in decreasing order of urbanization: Metro (located inside a metropolitan statistical area); Nonmetro Urbanized (nonmetro, with an urban population of 20,000 or more); Nonmetro Less Urbanized (nonmetro, with urban population of 2,500-19,999); and Completely Rural (nonmetro, with urban population under 2,500). Table 1 shows mean pull factors by urbanization code and trade center status for 1982, 1987, and 1992. The data show that pull factors are lower (leakages are higher) in more rural non-trade center counties, and that leakages from these counties increased from 1982 to 1992 . Among nonmetro nontrade center counties, urbanized counties had high and stable pull factors, averaging 0.977 in 1982; 0.981 in 1987; and 0.980 in 1992. This suggests that counties with larger towns, even those that are not regional trade centers, are able to retain most of their residents' retail purchases. Metro non-trade center counties increased retail trade retention, as their average pull factor rose from 0.816 in 1982 to 0.838 in 1992.

Less urbanized and completely rural non-trade center counties had lower pull factors than the more urbanized counties and declined even further from 1982 to 1992. Average pull factors for less urbanized non-trade center counties fell from 0.877 in 1982 , to 0.849 in 1987 , and to 0.837 in 1992 , a decrease of 0.040 in ten 


\section{TABLE 1}

Mean Retail Sales Pull Factors, by Degree of Urbanization and Trade Center Status, 1982-92

\begin{tabular}{|c|c|c|c|c|c|c|}
\hline \multirow[b]{2}{*}{ County type ${ }^{2}$} & \multirow[b]{2}{*}{$\mathbf{N}$} & \multicolumn{3}{|c|}{ Mean Pull Factor ${ }^{1}$} & \multicolumn{2}{|c|}{ Change } \\
\hline & & 1982 & 1987 & 1992 & 1982-87 & $1987-92$ \\
\hline \multicolumn{7}{|l|}{ Trade center counties } \\
\hline Metro & 330 & 1.090 & 1.094 & 1.093 & 0.004 & -0.001 \\
\hline \multicolumn{7}{|l|}{ Nonmetro } \\
\hline Urbanized & 155 & 1.106 & 1.122 & 1.123 & 0.016 & 0.001 \\
\hline Less urbanized & 63 & 1.158 & 1.163 & 1.183 & 0.005 & 0.020 \\
\hline Completely rural & 3 & 0.651 & 0.705 & 0.656 & 0.054 & -0.049 \\
\hline \multicolumn{7}{|c|}{ Non-trade center counties } \\
\hline Metro & 490 & 0.816 & 0.829 & 0.838 & 0.013 & 0.009 \\
\hline \multicolumn{7}{|l|}{ Nonmetro } \\
\hline Urbanized & 91 & 0.977 & 0.981 & 0.980 & 0.004 & -0.001 \\
\hline Less urbanized & 1,196 & 0.877 & 0.849 & 0.837 & -0.028 & -0.012 \\
\hline Completely rural & 774 & 0.633 & 0.594 & 0.569 & -0.039 & -0.025 \\
\hline
\end{tabular}

\footnotetext{
'Unweighted means.

${ }^{2}$ Trade center counties contain the highest-order town or city in a multicounty Rand McNally trading area. Metro counties are located within metropolitan statistical areas (MSAs). Nonmetro counties are outside MSAs. Urbanized counties have an urban population of 20,000 or more. Less urbanized counties have urban population of 2,500 to 19,999 . Completely rural counties have urban population under 2,500 .
}

years. Completely rural non-trade center county average pull factors fell from 0.633 in 1982 to 0.594 in 1987 and to 0.569 in 1992, representing a decrease of 0.064 in ten years. These results, using nationwide data, support previous studies' conclusions about low and declining pull factors in more rural communities.

The trend in pull factors for trade center counties was the mirror image of that for non-trade center counties. Average pull factors for less urbanized trade center counties rose from 1.158 in 1982 to 1.183 in 1992 . These counties contain smaller trade center towns (pop. 2,500-19,999) in the more rural trading areas and draw retail sales from less urbanized and completely rural non-trade center counties. Hence, this result is consistent with the decline in pull factors observed for less urbanized and completely rural non-trade center counties. More urbanized nonmetro trade center counties also experienced a slightly smaller increase in average pull factors from 1982 to 1992 , while metro trade center pull factors were fairly stable. The higher pull factors of less urbanized trade center counties compared with metro and more urbanized nonmetro counties reflects a higher degree of dependence on sales to residents from outside the county in smaller trade center counties, as compared with more urbanized trade centers. 
Table 2 shows mean pull factors for less urbanized and completely rural nontrade center counties by region for 1982-1992 to evaluate regional differences in pull factors for these county types. This table permits comparison of average pull factors, for similar county types vary across regions. Northeastern counties generally had the highest and most stable pull factors. Average pull factors for less urbanized non-trade center counties ranged from 0.850 for the Plains to 0.948 for the Mountain region in 1982. By 1992 that range was slightly broader: from 0.800 (Plains) to 0.927 (Northeast). The average pull factor for completely rural non-trade center counties in 1982 varied more than the average for less-urbanized counties. The South and West Coast had the lowest pull factors, averaging $\mathbf{0 . 5 8 2}$ and 0.577 , respectively, followed by the Plains and Mountain regions, with averages of 0.629 and 0.660 , respectively, and the Northeast and Midwest had the highest averages, at 0.767 and 0.705 , respectively.

Between 1982 and 1987 average pull factors for these county types fell in all regions, with the biggest decrease in the Mountain region and the slowest decrease in the Northeast. In the other four regions, decline in pull factors ranged from -0.020 to -0.031 for less urbanized counties and from -0.015 to -0.059 for completely rural counties. For less urbanized non-trade center counties average pull factors were generally more stable between 1987 and 1992, with only modest

TABLE 2

Mean Retail Sales Pull Factors by Region and County Type, Non-Trade Center Counties, 1982-92

\begin{tabular}{|c|c|c|c|c|c|c|}
\hline \multirow[b]{2}{*}{ County type ${ }^{2}$} & \multirow[b]{2}{*}{$\mathbf{N}$} & \multicolumn{3}{|c|}{ Mean Pull Factor ${ }^{1}$} & \multicolumn{2}{|c|}{ Change } \\
\hline & & 1982 & 1987 & 1992 & $1982-87$ & $1987-92$ \\
\hline \multicolumn{7}{|c|}{ Less urbanized nonmetro } \\
\hline Northeast & 59 & 0.946 & 0.940 & 0.927 & -.006 & -.013 \\
\hline Midwest & 314 & 0.877 & 0.846 & 0.840 & -.031 & -.006 \\
\hline South & 402 & 0.863 & 0.843 & 0.828 & -.020 & -.015 \\
\hline Plains & 256 & 0.850 & 0.824 & 0.800 & -.026 & -.024 \\
\hline Mountain & 116 & 0.948 & 0.873 & 0.870 & -.075 & -.003 \\
\hline West Coast & 40 & 0.909 & 0.879 & 0.890 & -.030 & .011 \\
\hline \multicolumn{7}{|c|}{ Completely rural nonmetro } \\
\hline Northeast & 13 & 0.767 & 0.764 & 0.795 & -.003 & .031 \\
\hline Midwest & 141 & 0.705 & 0.678 & 0.644 & -.027 & -.034 \\
\hline South & 250 & 0.582 & 0.567 & 0.533 & -.015 & -.034 \\
\hline Plains & 249 & 0.629 & 0.570 & 0.540 & -.059 & -.030 \\
\hline Mountain & 96 & 0.660 & 0.591 & 0.591 & -.069 & .000 \\
\hline West Coast & 17 & 0.577 & 0.538 & 0.556 & -.039 & .018 \\
\hline
\end{tabular}


decreases in four regions and an increase in the West Coast region. However, in the Plains region the average pull factor for less urbanized counties continued decreasing at nearly the same rate as 1982-87. For completely rural counties, pull factors continued to decline in the Midwest, South, and Plains from 1987 to 1992 , but stabilized or increased in the Northeast, West Coast, and Mountain regions. By 1992, average pull factors for completely rural counties were less than 0.600 in four regions. The regions with the highest pull factors for completely rural counties were the Midwest $(0.644)$, and the Northeast $(0.795)$.

While previous studies of pull factors concentrated on the Midwest and Plains regions, these data show that low and declining rural pull factors characterized other regions as well during the 1980s. The decline from 1982 to 1987 may have been a temporary phenomenon in the Northeast, Mountain, and West Coast regions, as pull factors were more stable in those regions from 1987 to 1992. Stone (1987) attributed decline in the retail sector in Iowa during the 1980s to the farm financial crisis of that period, and others have linked retail decline in small towns to structural changes in farming. The rapid decline in rural pull factors from 1982 to 1987 coincides with the worst years of the farm financial crisis, consistent with Stone's analysis. However, the pull factor decline is not confined to farm-oriented regions. The decline was just as rapid in regions such as the South, Mountain, and West Coast, where local economies have relatively low dependence on farming. In the most farm-dependent regions, the Midwest and Plains, the decline in pull factors was faster from 1987 to 1992, after the farm crisis had ended. This suggests that pull factor decline in that period represents a more widespread structural shift in the rural economy during the 1980s.

\section{Regression Analysis}

Since farm-reliant counties are concentrated in the Plains and Midwest, it is difficult to distinguish between regional effects on pull factors, urbanization effects, and effects of farm-reliance by comparing mean pull factors. In other words, are pull factors low in the Plains counties because they have farm-reliant economies, or is it due to some other factor that characterizes that region, such as sparse population? The final segment of the analysis estimates the effects of farm reliance on non-trade center pull factors, while holding constant urbanization, region, and other factors using regression analysis. An ordinary least squares equation was estimated for each year, using the county pull factor as the dependent variable. Explanatory variables include measures of farm reliance, urbanization, region, and several county characteristics.

The measure of farm reliance is the percent of the county's personal income derived from farming for each year. Previous work has suggested that farming 
communities may have higher sales leakages (lower pull factors) than other types of communities. This suggests a negative coefficient for this variable. It has also been suggested that leakages are increasing in farming communities. This suggests that the coefficient on farm reliance may be growing in absolute value over time. The farm reliance variable is the ratio of farm personal income to total personal income, obtained from Bureau of Economic Analysis (1995), times 100.

A set of three dummy variables corresponding to urbanized nonmetro, less urbanized nonmetro, and completely rural counties (metro is the reference category) are included to control for degree of urbanization. Dummy variables are also included for five of the six regions used earlier in this article (the Plains region is the reference region). Three continuous variables control for population density, county size, and highway access. Population density is the county population for each year (Bureau of Economic Analysis, 1995) divided by square miles of land area. Pull factors are expected to be higher in more densely populated counties; thus a positive coefficient is expected on this variable. When a county has fewer potential customers per square mile and economies of size are important for retailers, the market area from which a retail establishment draws customers will have to be geographically large (cover more counties) to meet the demand threshold population. In a densely populated region, even non-trade center counties may have sufficient population to support a full range of retail businesses, but in sparsely populated regions many counties will fail to reach the threshold population level for some retail business types and consequently will have low pull factors.

The log of total county land area in square miles, obtained from the Census of Agriculture, is included to control for physical size of the county. County size may account for some regional differences in pull factors, since western counties generally cover more territory than eastern counties. Counties that cover a larger land area are expected to have higher pull factors, since their residents would have to travel further to make purchases outside the county

Finally, a dummy variable measuring interstate highway access is included to control for the effect of county accessibility on retail trade leakage. This variable is equal to 1 if the county contains an exit from an interstate highway, zero otherwise. This variable was constructed by the author using a 1991 road atlas. It was not updated to take into account new roads opened from 1982 to 1992 . The overall effect of highway access is ambiguous, $a$ priori, since there are two potentially offsetting effects of highway access. Counties that are more accessible by interstate highway are more attractive locations for retail stores, tending to raise pull factors. However, highway access also makes it easier for residents to drive elsewhere to do retail shopping, tending to reduce pull factors. 
Table 3 shows the OLS estimates obtained using 2,551 non-trade center county observations for each year. The equations explain 27 to 29 percent of the variation in non-trade center county pull factors, and each has a number of significant explanatory variables. The coefficient on the farm reliance variable is negative in each equation, suggesting that farm-oriented counties have lower pull factors. In 1982, a 1 percentage point increase in farm income share is associated with a change of -0.005 in the pull factor, holding other things constant. In 1987 and 1992, the magnitude of the negative effect is slightly smaller, -0.003 .

Urbanization variables indicate that nonmetro urbanized and less urbanized counties tend to have higher pull factors than metro and completely rural counties. The urbanized dummy variable has the largest coefficient in each year, suggesting that urbanized nonmetro counties tend to have the highest pull factors among nontrade center counties. The less urbanized dummy variable has a positive coefficient of 0.165 that is slightly smaller in 1982 , but steadily decreases in magnitude in subsequent years, reaching 0.140 in 1992. This suggests an increase in sales leakage (decline in pull factors) for less urbanized counties that is not explained by other characteristics in the model. The completely rural dummy variables coefficient is not significantly different from zero, suggesting that there is no difference in pull factors between metro and completely rural counties, when other characteristics are held constant. Although the completely rural coefficients are not significantly different from zero in any of the three years, they display the same downward trend from 1987 to 1992 observed for the less urbanized dummy variable, indicating a trend toward increased sales leakage. Comparing coefficients for the three nonmetro county types shows that pull factors for less urbanized and completely rural counties have declined relative to those of urbanized counties. The difference between the coefficients for urbanized versus completely rural counties increases from 0.150 in 1982, to 0.176 in 1992 . The difference between urbanized and less urbanized dummy variable coefficients increased from 0.005 in 1982 to 0.026 in 1992.

Population density and county land area are positively associated with pull factors, as expected. These variables may account for much of the difference in mean pull factors across regions, since population density and county size vary from region to region. More densely populated counties in the Northeast and West Coast regions tend to have higher pull factors than more sparsely populated counties. The larger counties in the Mountain region also tend to have relatively high pull factors, although they are sparsely populated. Regional effects are weak, when other characteristics are held constant. In particular, population density and county size, which vary regionally, may explain much of the regional variation in mean pull factors. In the regression models, when these and other characteristics are held constant, the only regional dummy variable significantly different from 
TABLE 3

Pull Factor Regressions, Non-Trade Center Counties, 1982-92

\begin{tabular}{lccc} 
Explanatory Variable & 1982 & 1987 & 1992 \\
\hline Intercept & $0.708^{*}$ & $0.697^{*}$ & $0.692^{*}$ \\
Log (population density) & $(0.016)$ & $(0.017)$ & $(0.018)$ \\
& $0.064^{*}$ & $0.083^{*}$ & $0.078^{*}$ \\
Log (county land area) & $(0.007)$ & $(0.007)$ & $(0.008)$ \\
& $0.074^{*}$ & $0.094^{*}$ & $0.082^{*}$ \\
Percent of income from farming & $(0.010)$ & $(0.010)$ & $(0.011)$ \\
& $-0.0053^{*}$ & $-0.0034^{*}$ & $-0.0030^{*}$ \\
Interstate highway & $(0.0008)$ & $(0.0006)$ & $(0.0007)$ \\
& $0.058^{*}$ & $0.054^{*}$ & $0.070^{*}$ \\
Northeast & $(0.011)$ & $(0.011)$ & $(0.012)$ \\
Midwest & 0.020 & 0.019 & 0.022 \\
& $(0.022)$ & $(0.024)$ & $(0.026)$ \\
West Coast & -0.013 & -0.014 & -0.015 \\
& $(0.015)$ & $(0.015)$ & $(0.017)$ \\
Mountain & -0.002 & -0.022 & -0.008 \\
& $(0.026)$ & $(0.028)$ & $(0.031)$ \\
South & 0.035 & 0.001 & 0.021 \\
& $(0.018)$ & $(0.020)$ & $(0.022)$ \\
Urbanized nonmetro & $-0.055^{*}$ & $-0.058^{*}$ & $-0.057^{*}$ \\
Less urbanized nonmetro & $(0.014)$ & $(0.015)$ & $(0.017)$ \\
Completely rural nonmetro & $0.170^{*}$ & $0.171^{*}$ & $0.166 *$ \\
\hline F-statistic. $\mathrm{R}^{2}$ & $(0.025)$ & $(0.027)$ & $(0.030)$ \\
\hline & $0.165^{*}$ & $0.155^{*}$ & $0.140^{*}$ \\
& $(0.015)$ & $(0.016)$ & $(0.023)$ \\
& 0.020 & 0.020 & -0.010 \\
& $(0.020)$ & $(0.020)$ & $(0.023)$ \\
\hline & 0.27 & 0.29 & 0.27 \\
& 78.70 & 87.99 & 79.19 \\
\hline
\end{tabular}

Estimated with ordinary least squares, using data on non-trade center counties only, $N=2551$. Standard errors shown in parentheses. Excluded categorical dummy variables include Plains region and metro county type. *Denotes significantly different from zero at 0.05 level. 
zero is the South, with negative coefficients in each year. This indicates that southern counties have lower pull factors than counties in the Plains (the region whose dummy was excluded from the model). This result, combined with the nonsignificant coefficients for the other regional dummies, suggests that there is no significant difference in pull factors in the Plains, West Coast, Northeast, Midwest, and Mountain regions, while pull factors are lower in the South when other factors are held constant.

Counties with an interstate highway tend to have higher pull factors, holding other things constant. This suggests that the improved accessibility associated with highway access attracts retail businesses. In 1982 and 1987, counties with an interstate highway had pull factors 0.058 higher than other counties, holding other things constant. In 1992 the interstate highway coefficient rose to 0.070 , suggesting that the effect of highway access rose slightly from 1987 to 1992.

\section{CONCLUSION}

This study reported estimates of pull factors for over 3,000 U.S. counties, using Census of Retail trade data for 1982, 1987, and 1992. Pull factors average 0.78 for counties without a trade center and 1.11 for counties containing a trade center, but pull factors vary considerably by degree of urbanization and region. Analysis of pull factors confirms the findings of previous studies that pull factors are declining in more rural counties, in contrast to stability in pull factors for more urbanized counties. Decline in rural pull factors was faster between 1982 and 1987 than from 1987 to 1992 . The decline in rural pull factors appears not only in comparisons of means, but also in regression models that hold constant other county characteristics, such as population density, farm reliance, and interstate highway access.

The results of this study indicate that retail concentration is not a regional or localized problem. Neither is it limited to farm-oriented communities, nor is it the result of one company's expansion strategy. Wal-Mart, the retail chain that has successfully targeted rural consumers, has come to symbolize this trend. Citizens and local zoning officials motivated to block the building of Wal-Mart and other retail stores should be aware that increasing sales leakage from smaller counties appears to represent a more fundamental structural change in the rural economy. This study could not identify the cause of this change, but it could be due to a number of potential factors, including lower transportation costs for consumers, preferences for one-stop shopping in centrally-located retail centers, or economies of scale and scope in retailing and greater pressure to reduce cost-price margins. 
This study contributes to knowledge of regional retail trade patterns, but additional work is needed to examine patterns for finer subdivisions of retail trade at the 2-digit SIC level; and for towns rather than counties. Future research might also study in greater detail the influence of local characteristics on pull factors, the importance of sales leakage in reducing export base multipliers, and the economic impact of sales leakages in terms of jobs and income.

\section{ENDNOTES}

1. Other factors, $X_{\mathrm{i}}$, might also be included, but it is more difficult to find data on other variables besides income that would be useful for a cross-sectional analysis of retail purchases. Possible bias in the estimate of $\alpha_{1}$ due to correlation between $\mathrm{y}$ and $\mathrm{X}$ is not a great concern, since the interest here is in prediction of $\mathrm{z}$, rather than obtaining an unbiased estimate of $\alpha_{1}$.

2. Most studies of pull factors use the state as the region over which retail sales equal retail demand, because state per capita sales or something similar is used in the denominator of the pull factor. The trading area certainly is a superior choice of regions to the state, since states are political boundaries and much retail trade overlaps state boundaries. Other possibilities include BEA economic areas, commuting zones, or an analyst's self-defined regions.

3. The data include sales for both employers and nonemployers. Suppressed data for a few counties were imputed by the author.

4. Measurement error and unmeasurable factors probably account for much of the unexplained variation in per capita sales. In an attempt to increase the explanatory power, demographic variables from the 1990 Census of Population were added to the model in preliminary work, but the increase in explanatory power was modest. Many of the demographic variables are also correlated with one another. The marginal increase in explanatory power did not seem to justify the increased complexity of adding variables to the model, so they were dropped. The resulting pull factor estimates were not very sensitive to changes in the per capita sales model. Note also that, while per capita sales regressions have a relatively modest $R^{2}$, a regression of total sales per county on population and per capita income explains nearly all the variation in sales.

5. Note that standard pull factor formulas that use state-level per capita sales or sales-income ratio as the denominator also guarantee that an identity like (10) is satisfied for the state.

6. A complete listing of counties showing pull factors and per capita retail sales for 1982, 1987 and 1992, sorted by trading area, can be obtained directly 
from the author. It is available in hard copy as a LOTUS 1-2-3 file or an ASCII file.

7. The distributions of trade center and non-trade center county pull factors are influenced by the pull factor computation method. Recall that the method used here assumes that all retail trade takes place within the basic trading area, hence predicted retail demand equals retail sales summed over the trading area. This assumption ensures that at least one county in the area will have a pull factor greater than 1.0, except for trading areas consisting of only one county. The reader should be aware that misleading results may occur for some trading areas. For example, the Myrtle Beach, South Carolina, area has only one county, which has extremely high per capita sales. With this method, the Myrtle Beach county has a pull factor of 1.0, although it clearly draws considerable retail sales (through tourism) from outside the county. In some midwestern trading areas, all counties have low per capita sales, suggesting that even the county identified as a trading center may, in fact, have sales leakage to a larger city outside the trading area. Yet with this computation method, the trading center has a pull factor greater than 1.0. If an analyst were concerned with these unusual cases, a broader aggregate, such as the state, BEA economic area, or major trading area could be used as the base for computing pull factors.

\section{REFERENCES}

Ayres, J.S., F.L. Leistritz, and K.E. Stone. Revitalizing the Retail Trade Sector in Rural Communities: Lessons from Three Midwestern States. Ames, Iowa: North Central Regulatory Center for Rural Development RRD 162, November 1992.

Bureau of Economic Analysis. Regional Economic Information System CD-ROM. Washington, DC: U.S. Department of Commerce, 1995.

Butler, M.A. Rural-Urban Continuum Codes for Metro and Nonmetro Counties. USDA-ERS Staff Report 9028. April 1990.

Darling, D.L., and J.S. Tan. "Retail Trade Patterns of Rural Kansas." Choices (Second Quarter 1990): 34-35.

Deller, S.C., J.C. McConnen, J. Holden, and K. Stone. "The Measurement of a Community's Retail Market." Journal of the Community Development Society 22(1991): 68-83.

Fox, Karl A. "The Study of Interactions Between Agriculture and the Nonfarm Economy: Local, Regional and National." Journal of Farm Economics 44(1962): 1-34. 
Gruidl, J.J., and Dimitri Andrianacos. "Determinants of Rural Retail Trade: A Case Study of Illinois." The Review of Regional Studies 24(1994): 103-118.

Harris, T.R., and D.S. Shonkwiler. "Application of Maximum Likelihood to a Bivariate Two-limit Tobit Model for Estimation of Rural Retail Sales Potential." The Review of Regional Studies 24(1994): 143-160.

Harris, T.R., G.W. Smith, and M.B. Mooney. "An Alternative Approach to Trade Area Analysis." Journal of the Community Development Society 21(1990): 116-128.

Mulligan, G.F. "Agglomeration and Central Place Theory: A Review of the Literature." International Regional Science Review 9(1984):1-42.

Rand McNally. 1990 Commercial Atlas and Marketing Guide. Chicago: Rand McNally, 1990.

Senf, D.R. Shift-Share Analysis of Rural Retail Trade Patterns. Regional Science Perspectives 18(1988): 29-37.

Shaffer, Ron. Community Economics: Economic Structure and Change in Smaller Communities. Ames, IA: Iowa State University Press, 1989.

Stone, K.E. "Impact of the Farm Financial Crisis on the Retail and Service Sectors of Rural Communities." Agricultural Finance Review 47(1987):40-47.

Stone, K.E., and J.M. McConnen, Jr. Retail Sales Migration in the Midwestern United States. Ames, IA: Iowa State University, Dept. of Economics, 1980.

Thill, J.C. "Spatial Competition and Market Interdependence." Papers in Regional Science 71(1992):259-275.

U.S. Bureau of the Census. 1992 Economic Censuses CD-ROM. Vol. 1: Report Series, Release 1C, 1994.

Yanagida, J.F., B.B. Johnson, J. Young, and M. Lundeen. "An Analysis of Economic and Noneconomic Factors Affecting Retail Sales Leakages." Review of Regional Studies 21(1991): 53-64. 
